Bull. Egypt. Soc. Physiol. Sci. Vol. (41) Issue (4), 441-457

\author{
Bull. of Egyp. Soc. Physiol. Sci. \\ (Official Journal of Egyptian Society for Physiological Sciences) \\ (pISSN: 1110-0842; eISSN: 2356-9514)
}

\title{
Could omega-3 fatty acids preserve endothelial function in a rat model of rheumatoid arthritis?
}

\author{
Eman A. Allam *, Eman M. Omar* \\ * Medical Physiology department, Faculty of Medicine, Alexandria University, Egypt
}

Submit Date: Dec 2, 2020

Revise Date: Jan 4, 2021

Accept Date : Jan 21,2021

\section{Keywords}

- Rheumatoid arthritis

- Endothelial

dysfunction

- Omega-3

- Vascular cell

adhesion molecule-1

- Tumor necrosis

factor- $\alpha$

Malondialdehyde

- Nitric oxide

\begin{abstract}
Background: Endothelial dysfunction is claimed to be the cause of increased risk for cardiovascular diseases in rheumatoid arthritis (RA) patients. Omega-3 fatty acids is a promising drug in this field; however, its exact effects on endothelial functions are not fully understood. Aim of the work: This study aimed to evaluate the effect of omega-3 fatty acids on endothelial reactivity and some markers of endothelial dysfunction [Vascular cell adhesion molecule-1 (VCAM-1), tumour necrosis factor alpha (TNF- $\alpha$ ), Malondialdehyde (MDA) and NOS activity] in a rat model of rheumatoid arthritis. Material \& methods: Thirty male rats were divided into 3 groups (control, untreated RA, and RA group with omega-3 supplementation). RA induction was done by intradermal injection of heat-killed Mycobacterium butyricum and was confirmed by clinical signs of arthritis on day 11. In the treated group, omega-3 was given daily via gastric gavage starting from day 11 until the end of the study. The study duration was 30 days for all groups starting from the day of induction. At the end of the study, rats were sacrificed, blood samples were collected for VACM-1, TNF- $\alpha$, MDA and nitrite measurement and thoracic aortae were taken to test vascular reactivity. Results: All markers increased while vascular reactivity decreased significantly after RA induction. Omega-3 treatment significantly decreased all biochemical markers and restored normal vascular reactivity in the treated group.
\end{abstract}

Eman Ahmed Allam, Medical Physiology department, Faculty of Medicine, Alexandria University, Egypt, E-mail: emanallam85@yahoo.com,Eman.maher@alexmed.edu.eg, Tel: 01224711331 


\section{INTRODUCTION}

Rheumatoid arthritis (RA) is the commonest chronic systemic autoimmune disease. It is characterized by persistent synovitis, systemic inflammation, and extra-articular manifestations. ${ }^{(1)}$ Due to the presence of multiple treatment options, RA is no longer considered as a life-threatening condition. However, cardiovascular mortality (ischemic heart disease, strokes) represents the cause of death among $50 \%$ of RA patients. (2) The cause for increased cardiovascular diseases in RA patients is the endothelial dysfunction (ED) accompanying the disease. ED is a preclinical marker for abnormalities of vascular function and structure. ED induces reduced vasodilatation, proinflammatory status, and prothrombotic properties. (3, 4) Precise identification of the pathophysiology of ED in RA is mandatory for the discovery of therapeutic interventions to decrease $\mathrm{CV}$ risk in RA patients especially if intervention is started early during the reversible ED stage.

Oxidative stress and chronic inflammation are claimed to have an important role in this ED associating RA. Chronic inflammatory diseases are usually linked with increased oxidative stress that plays an important role in disease activity. ${ }^{(5)}$ In addition, pro-inflammatory mediators such as interleukin-1 beta (IL-1 $\beta$ ) and tumor necrosis factor- $\alpha(\mathrm{TNF}-\alpha)$ play an essential role as the vascular endothelium is an important target for TNF- $\alpha$. (6) Also, endothelial cell adhesion molecules, especially vascular cell adhesion molecule-1 (VCAM-1) have an important role in ED. They are expressed at the surface of the endothelial cells and bind leukocyte-specific receptors, leading to increased affinity of leukocytes to the endothelial surface and eventually increased transendothelial migration. ${ }^{(7)}$ Change in endothelial nitric oxide (NO) bioavailability is suggested to contribute in endothelial dysfunction in RA patients. Indeed, changes in endothelial nitric oxide synthase (eNOS) and inducible nitric oxide synthase (iNOS) activity may be considered as key pathophysiological mechanisms. ${ }^{(8,9)}$

Due to the high mortality rate from vascular complications in RA patients, it is necessary to pay close attention to the therapeutic options for these complications. ${ }^{(10)}$ One of the promising drugs in this field is omega-3 fatty acids. Omega-3 polyunsaturated fatty acids (PUFAs) are essential fatty acids that have potent immune-modulatory activities. Many studies have demonstrated that omega-3 have a variety of bioactive actions such as anti-inflammatory properties (11, 12), antioxidant effects $(13,14)$ and improvement of endothelial function. ${ }^{(15,16)}$ However, the effects of omega-3 in endothelial dysfunction in RA disease are not completely understood especially during the acute stage of the disease during which the endothelial dysfunction is the only present cardiovascular event and is reversible before actual occurrence of cardiovascular complications (hypertension and atherosclerosis). This study aimed to study the effect of induction of RA in a rat model on vascular reactivity, serum malonaldehyde (MDA), TNF- $\alpha$, VCAM-1, nitrite ( as a marker for NOS activity) and to evaluate the effect of omega-3 treatment on the same parameters. 


\section{MATERIAL AND METHODS:}

\section{Experimental animals:}

Thirty adult male albino Wistar rats weighing 125150 grams were used in this study. Rats were purchased from and housed in the Medical physiology department, Faculty of Medicine, Alexandria University, Egypt. They were kept in clean wire mesh cages with free access to a regular chow meal and tap water under conventional boarding conditions. Rats were selected carefully free of gait disturbance, swollen joints, or paws. The experimental procedures were conducted in accordance with the Guide for the Care and Use of Laboratory Animals (8th edition, National Academies Press) and were approved by Research Ethics Committee, Alexandria Faculty of Medicine (IRB code 00012098- FWA: No. 00018699; membership in International Council of Laboratory Animal science organization ICLAS). The serial registration number of this study is 0304028.

\section{Study design:}

After acclimatization for one week, rats were divided randomly into three groups 10 rats each.

Group I: control group (negative control)

Group II: RA induced group (positive control)

Group III: RA induced group with omega-3 supplementation.

Induction of RA in 20 rats was done by intradermal injection at the tail base of $120 \mu \mathrm{L}$ of 1 $\mathrm{mg}$ of heat-killed Mycobacterium butyricum suspended in $0.1 \mathrm{ml}$ of mineral oil (Complete Freund's adjuvant) (Sigma-Ardlich, Egypt). (17) Rats in the control group were injected with a similar amount of mineral oil. All injections were preceded by sterilization of skin with betadine antiseptic solution. The day of injection was considered as day zero for all groups. The induction of RA was confirmed by clinical signs of arthritis on day 11 of induction using the clinical scoring system that will be mentioned later in details.

In group III, Omega-3 was given orally once daily at a dose of $300 \mathrm{mg} / \mathrm{kg}$ (equivalent to $0.2 \mathrm{ml}$ fish oil/rat). ${ }^{(18)}$ Omega-3 was used in the form of fish oil-containing gelatinous capsules (Kirkland signature dietary supplements). Each capsule was carefully evacuated by a $1 \mathrm{ml}$ syringe and given to rats. Rats in the untreated RA group were administered an oral dose of oily vehicle (corn oil) as a placebo so that all rats were exposed to the same circumstances. Treatment was performed orally via a metallic gastric tube (gavage). Adequate measures were taken to minimize pain or discomfort. Treatment with either omega-3 or vehicle started from day 11 after the induction of RA (appearance of clinical arthritis) and continued till the end of the study. The study duration was 30 days from the day of induction. ${ }^{(19)}$

At the end of the study, the clinical scoring of arthritis was repeated. Then all rats were anesthetized by ether inhalation, sacrificed by decapitation, and samples of blood were collected by cardiac puncture. Blood was collected in clean dry, non-heparinized test tubes for separation of serum. The separation of serum was done using centrifugation at $3000 \mathrm{rpm}$ for 20 minutes. Serum was stored at $-20^{\circ} \mathrm{C}$ for biochemical assessment. Thoracic aortae were removed and immediately used to test vascular reactivity to acetylcholine (Ach) and Norepinephrine (NE) using a power lab AD instrument. ${ }^{(20,21)}$ 
Clinical scoring of the arthritis model: ${ }^{(22)}$

Scoring of arthritis was performed on days 0,11 , 21 , and 30 respectively. It was done by two persons independently, without knowing the clinical scoring history of the rat. Clinical scoring was done on a subjective scale ranging from 0 to 1.5 for each paw (Table 1). In each paw, the five fingers or toes and one big joint (wrist or ankle) were examined. The ankle and tarsus joints were considered the same. This score provides only a subjective quantification of arthritis.

\section{Vascular reactivity (Biological in vitro study)}

(Isometric tension study): ${ }^{20,21)}$

For assessment of endothelial dysfunction, curves of contraction-relaxation response of the isolated aortic rings were plotted using the AD Instruments Power Lab 8/35 data acquisition system.

Immediately after isolation of the thoracic aortae, they were put in a dissecting dish containing Krebs solution (the buffer composition in $\mathrm{mM}$ is $\mathrm{NaCl}$ : 118.3, $\mathrm{CaCl}_{2}: 1.87, \mathrm{KCl}: 4.69, \mathrm{~K}_{2} \mathrm{HPO}_{4}: 1.03$, $\mathrm{MgSO}_{4}: 1.20, \mathrm{NaHCO}_{3}: 25$, and glucose 11.1). Careful dissection of the thoracic aortae was done with removal of any perivascular adipose tissue, connective tissue, and blood clots. Subsequently, the aortae were cut into rings $3-5 \mathrm{~mm}$ width. Each ring was carefully attached to a force-sensitive isometric transducer (Model MLT0202, AD Instruments). Then, the aortic rings were immersed in an organ bath chamber containing Krebs solution. This solution was aerated with carbogen continuously (mixture of $95 \% \mathrm{O}_{2}$ and $5 \% \mathrm{CO}_{2}$ ) and maintained at $37^{\circ} \mathrm{C}$.

Then, tissues were allowed to equilibrate for one hour after applying a passive baseline tension of 2 grams. Repeated wash was done every fifteen minutes. After equilibration, cumulative concentrations $\left(10^{-6}, 10^{-5}\right.$ and $\left.10^{-4} \mathrm{~mol} / \mathrm{L}\right)$ of $\mathrm{NE}$ were added to the solution to obtain a doseresponse curve (constrictor response). Following, curves demonstrating cumulative concentration-response for Ach's $\left(10^{-7}, 10^{-5}\right.$, and $10^{-3} \mathrm{~mol} / \mathrm{L}$ ) relaxing action on the NE precontracted rings were recorded. Responses were expressed as a percentage of relaxation by reduction of NE-peak response.

Data were acquired by a Power Lab $8 / 35$ data acquisition system (Model No PL3508/P, AD Instruments Pty Ltd, Castle Hill, Australia) and data analysis was obtained by the Lab Chart Pro Dose response module analysis software, where dose-response curves were automatically plotted.

\section{Biochemical Measurements (VCAM-1, MDA, TNF- $\alpha$ and nitrite):}

Using kits supplied by Abcam Egypt, serum TNF$\alpha$ and VCAM-1 were measured by Enzyme-linked immunosorbent assay (ELISA) ${ }^{23,24)}$ according to manufacturer's instructions. Serum MDA as an oxidative stress marker was measured by colorimetric method. ${ }^{(25)}$ Serum nitrite level as an indicator for nitric oxide synthase activity was measured by Griess calorimetric method. (26)

Data and statistical analysis: (27)

Values are presented as means \pm standard deviation (SD). Data were analyzed using IBM SPSS statistics, version 22.0 (IBM Inc.). Results were analyzed using one-way analysis of variance (ANOVA) test. Comparison of two variables between 2 groups was assessed using Duncan's post Hoc test. Analysis of the relationship between two parameters was determined by linear regression analysis and Pearson correlation coefficient was calculated between these variables. 
$\mathrm{P}$ value which is less than 0.05 was considered statistically significant.

\section{RESULTS}

\section{The clinical evaluation in RA rats:}

The first clinical signs of arthritis (redness or swelling) appeared between day 11 and day 14 in groups II \& III after induction. From day 11

\section{Table 1: Clinical scoring system for arthritis}

\begin{tabular}{|c|c|}
\hline Clinical scoring for each paw & $\begin{array}{r}\text { Scoring for fingers or toes: } \\
\text { - Swelling or redness of each finger : 0.1 } \\
\text { - Redness or swelling of all fingers in the paw }: \mathbf{0 . 5}\end{array}$ \\
\hline & $\begin{array}{ll}\text { Scoring for the big joint (wrist or ankle): } \\
-\quad \text { Mild swelling or redness }: 0.5 \\
-\quad \text { Intense swelling or severe redness }: \mathbf{1}\end{array}$ \\
\hline \multicolumn{2}{|c|}{$\begin{array}{l}\text { - Arthritis score for each paw is from } \underline{0 \text { to } 1.5} \\
\text { - Total score for the four paws is from } \underline{0 \text { to } 6}\end{array}$} \\
\hline \multicolumn{2}{|c|}{ Categories for clinical scoring } \\
\hline Grade 0 & Score of arthritis that equals 0 \\
\hline Grade 1 & Score of arthritis is from 0.1 to 0.9 \\
\hline Grade 2 & Score of arthritis is from 1 to 1.9 \\
\hline Grade 3 & Score of arthritis is from 2 to 2.9 \\
\hline Grade 4 & Score of arthritis is from 3 to 3.9 \\
\hline Grade 5 & Score of arthritis is 4 or more \\
\hline
\end{tabular}

Table (2): Comparison between groups II \& III regarding clinical scoring of arthritis

\begin{tabular}{|c|c|c|c|}
\hline & Group I "Control" & Group II "RA" & $\begin{array}{c}\text { Group III } \\
\text { "RA+ omega-3" }\end{array}$ \\
\hline $\begin{array}{l}\text { Day } 11 \\
\text { Range } \\
\text { Mean } \pm \text { S.D. }\end{array}$ & 0.0 & $\begin{array}{c}0.5-1.2 \\
0.81 \pm 0.247\end{array}$ & $\begin{array}{c}0.6-1.1 \\
0.89 \pm 0.173\end{array}$ \\
\hline t-test & & $\begin{array}{l}1.03 \\
0.198\end{array}$ & \\
\hline $\begin{array}{l}\text { Day } 21 \\
\text { Range } \\
\text { Mean } \pm \text { S.D. }\end{array}$ & 0.0 & $\begin{array}{c}2.8-3.6 \\
3.2 \pm 0.262\end{array}$ & $\begin{array}{c}0.5-2.5 \\
1.5 \pm 0.667\end{array}$ \\
\hline $\begin{array}{l}\text { t-test } \\
\text { p }\end{array}$ & & $\begin{array}{c}3.01 \\
0.002 *\end{array}$ & \\
\hline $\begin{array}{l}\text { Day 30 } \\
\text { Range } \\
\text { Mean } \pm \text { S.D. }\end{array}$ & 0.0 & $\begin{array}{c}2.9-3.8 \\
3.44 \pm 0.350\end{array}$ & $\begin{array}{c}0.5-2.0 \\
1.26 \pm 0.595\end{array}$ \\
\hline $\begin{array}{l}\text { t-test } \\
\text { p }\end{array}$ & & $\begin{array}{c}3.28 \\
0.001 *\end{array}$ & \\
\hline
\end{tabular}

* : Significant difference when $\mathbf{P}<\mathbf{0 . 0 5}$

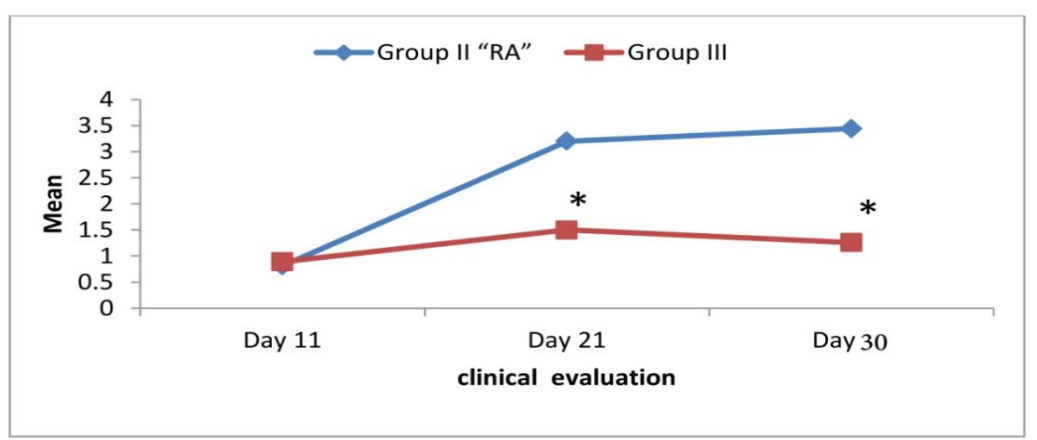

Figure 1: The clinical scoring in RA rats in groups II \& III

*: Significantly different in comparison to untreated RA group II 
Vascular reactivity (Biological in vitro study)

\section{(Isometric tension study):}

Cumulative concentrations of NE $\left(10^{-6}, 10^{-5}\right.$ and $10^{-4} \mathrm{~mol} / \mathrm{L}$ ) induced vasoconstrictor response in a dose-dependent manner in the aortic ring isolated from all groups, with maximum contraction achieved at $10^{-4} \mathrm{~mol} / \mathrm{L}$ (Figure 2). The maximally contracted aortic rings of the normal control rats showed a dose-dependent relaxant response to cumulative doses of Ach $\left(10^{-7}, 10^{-5}\right.$, and $10^{-3}$ mol/L). Results revealed a marked significant reduction in Ach-induced relaxation in maximally contracted rings of the non-treated RA rats versus those of the normal control rats in response to the three concentrations of acetylcholine $(\mathrm{P}=0.033$ at Ach $10^{-7}, \mathrm{P}=0.001$ at Ach $10^{-5} \& \mathrm{P}=0.001$ at Ach $\left.10^{-3}\right)$. Treatment with omega-3 attained a significant improvement of vascular reactivity demonstrated by a significantly enhanced Achinduced relaxant response versus those of the non- treated rats in response to all doses of acetylcholine $\left(\mathrm{P}=0.042\right.$ at Ach $10^{-7}, \mathrm{P}=0.008$ at Ach $10^{-5} \& \mathrm{P}=0.038$ at Ach $10^{-3}$ ) (Figure 3).

\section{Biochemical Measurements (VCAM-1, TNF- $\alpha$, MDA and nitrite):}

Serum VCAM-1, MDA, TNF- $\alpha$ and nitrite were increased significantly after RA induction in the group II ( $10 \pm 1.3 \mathrm{ng} / \mathrm{ml}, 8.9 \pm 1.6 \mathrm{nmol} / \mathrm{ml}, 18.1 \pm$ $0.9 \mathrm{ng} / \mathrm{ml} \& 5 \pm 1.07 \mu \mathrm{mol} / \mathrm{L}$ respectively) in comparison to the group I ( $5 \pm 0.45 \mathrm{ng} / \mathrm{ml}, 3.5 \pm$ $0.7 \mathrm{nmol} / \mathrm{ml}, 3 \pm 0.5 \mathrm{ng} / \mathrm{ml} \& 1.35 \pm 0.45 \mu \mathrm{mol} / \mathrm{L}$ respectively) with $(\mathrm{P}=0.002$ for $\mathrm{VCAM}-1, \mathrm{P}=$ 0.002 for MDA, $\mathrm{P}=0.001$ for TNF- $\alpha$ and $\mathrm{P}=0.001$ for nitrite). Treatment with omega-3 significantly decreased VCAM-1 (7.2 $\pm 1.42 \mathrm{ng} / \mathrm{ml}), \operatorname{MDA}(5.2$ $\pm 1.2 \mathrm{nmol} / \mathrm{ml}), \mathrm{TNF}-\alpha(7.3 \pm 0.9 \mathrm{ng} / \mathrm{ml}) \&$ nitrite $(2.78 \pm 0.76 \mu \mathrm{mol} / \mathrm{L})$ in group III in comparison to the group II with $(\mathrm{P}=0.36$ for VCAM- $1, \mathrm{P}=0.024$ for MDA, $\mathrm{P}=0.001$ for TNF- $\alpha \& \mathrm{P}=0.001$ for nitrite). (Figure $4 \mathrm{a}, \mathrm{b}, \mathrm{c}, \mathrm{d}$ )

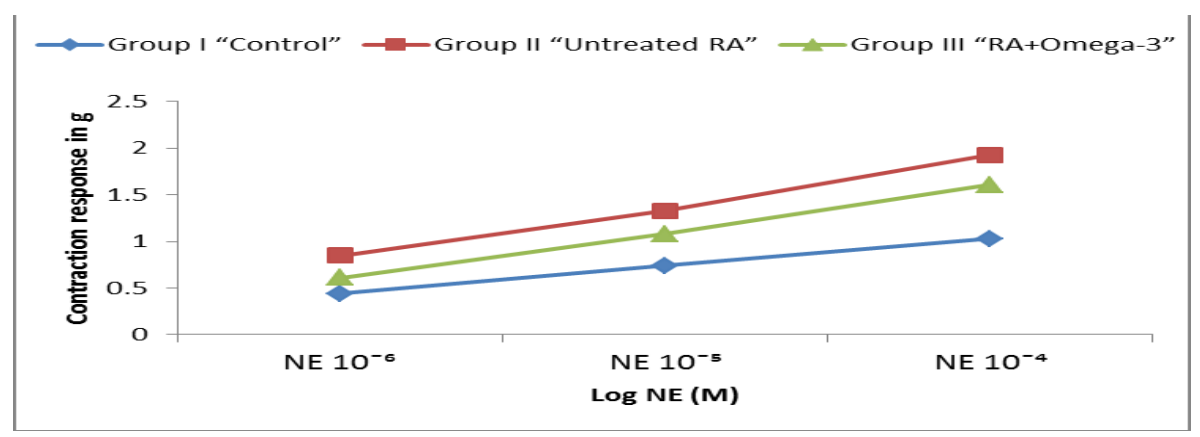

Figure 2: Changes in aortic rings vascular reactivity in terms of contraction responses to cumulative doses of NE in all studied groups

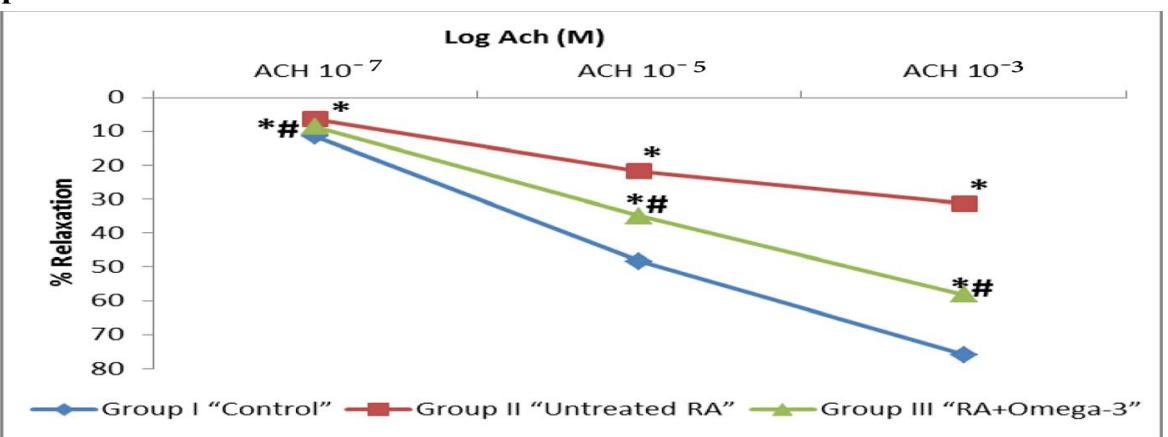

Figure 3: Percentage relaxation of NE pre-contracted rings in response to cumulative doses of Ach in all studied groups

*: Significantly different in comparison to the control group

\# : Significantly different in comparison to untreated RA group 

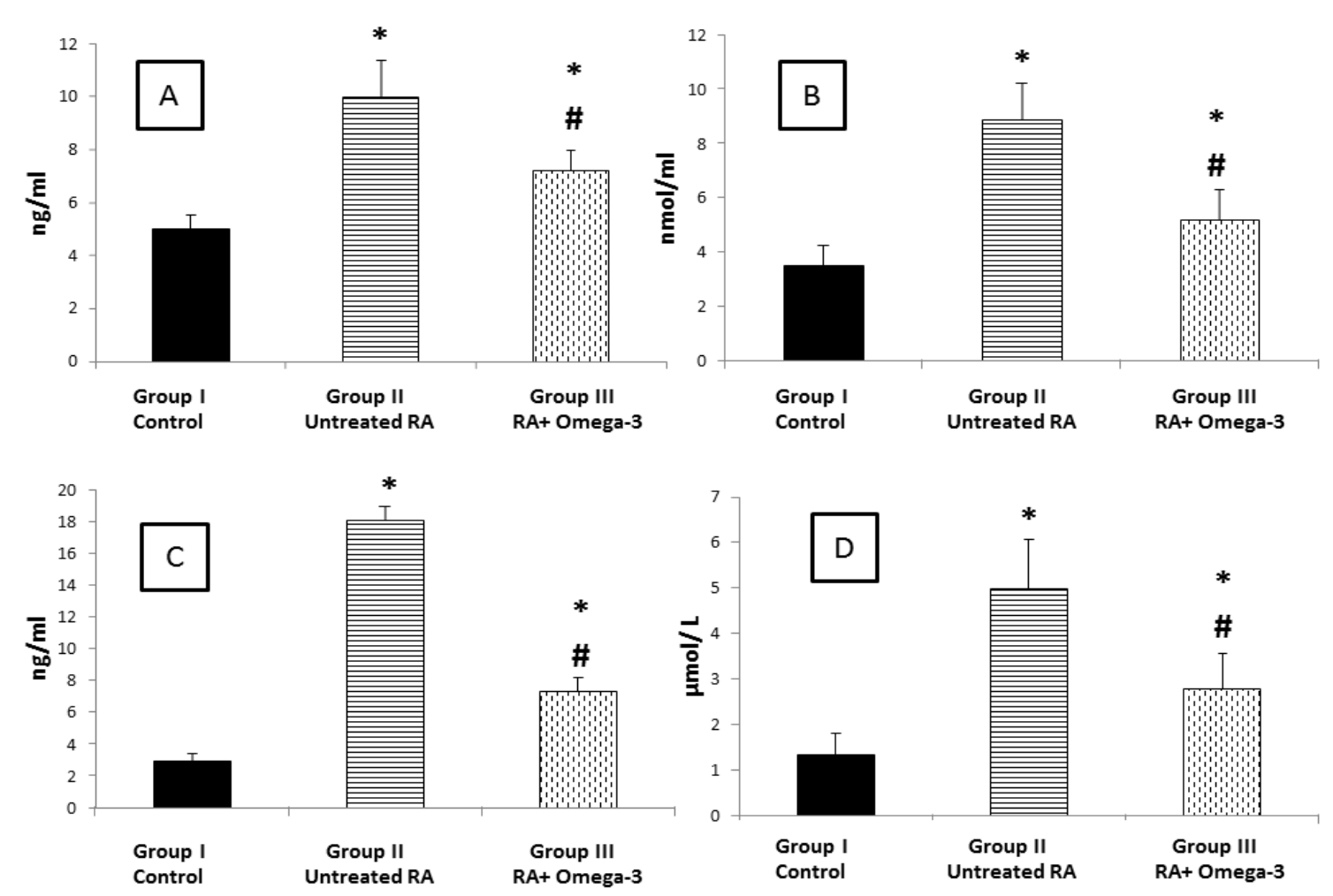

Figure 4: Biochemical measurements (VCAM-1, MDA, TNF- $\alpha$ \& Nitrite) in all studied groups (A: Serum VCAM-1, B: Serum MDA, C: Serum TNF-a, D: Serum Nitrite)

Results are represented as mean \pm SD, statistically significant difference when $P<0.05$

*: Significantly different in comparison to control group

\#: Significantly different in comparison to untreated RA group

Table (3): Correlation between biochemical parameters and Ach induced relaxation in all studied groups

\begin{tabular}{|c|c|c|c|c|}
\hline & & $\begin{array}{c}\text { \% relaxation } \\
\text { Ach } 10^{-7} \\
\end{array}$ & $\begin{array}{c}\text { \% relaxation } \\
{\text { Ach } 10^{-5}}^{-5} \\
\end{array}$ & $\begin{array}{c}\text { \% relaxation } \\
\text { Ach } 10^{-3} \\
\end{array}$ \\
\hline \multirow{2}{*}{ VCAM-1 } & Pearson Correlation (r) & \multirow{2}{*}{$\begin{array}{c}-0.652^{*} \\
0.0001\end{array}$} & \multirow{2}{*}{$\begin{array}{c}-0.677^{*} \\
0.0001\end{array}$} & \multirow{2}{*}{$\begin{array}{l}-0.72 * \\
0.0001\end{array}$} \\
\hline & P-value & & & \\
\hline \multirow{2}{*}{ MDA } & Pearson Correlation (r) & \multirow{2}{*}{$\begin{array}{l}-0.597^{*} \\
0.0001\end{array}$} & \multirow{2}{*}{$\begin{array}{c}-0.557^{*} \\
0.001\end{array}$} & \multirow{2}{*}{$\begin{array}{c}-0.768 * \\
0.0001\end{array}$} \\
\hline & P-value & & & \\
\hline \multirow{2}{*}{ TNF-alpha } & Pearson Correlation (r) & \multirow{2}{*}{$\begin{array}{c}-0.456^{*} \\
0.017\end{array}$} & \multirow{2}{*}{$\begin{array}{c}-0.476^{*} \\
0.012\end{array}$} & \multirow{2}{*}{$\begin{array}{c}-0.461 * \\
0.016\end{array}$} \\
\hline & P-value & & & \\
\hline \multirow{2}{*}{ Nitrite } & Pearson Correlation (r) & \multirow{2}{*}{$\begin{array}{l}-0.784 * \\
0.0001\end{array}$} & \multirow{2}{*}{$\begin{array}{c}-0.582 * \\
0.001\end{array}$} & \multirow{2}{*}{$\begin{array}{c}-0.569^{*} \\
0.001\end{array}$} \\
\hline & P-value & & & \\
\hline
\end{tabular}

\section{* : Significant correlation when $\mathbf{P}<\mathbf{0 . 0 5}$}

Table (4): Correlation between the biochemical parameters (VCAM-1, TNF- $\alpha$, MDA\& Nitrite) in all studied groups

\begin{tabular}{|c|c|c|c|c|}
\hline \multirow{2}{*}{ VCAM-1 } & TNF- $\alpha$ & MDA & Nitrite \\
\cline { 2 - 3 } & Pearson Correlation (r) & $0.582^{* *}$ & $0.803^{* *}$ & $0.794^{* *}$ \\
\cline { 2 - 2 } TNF- $\alpha$ & 0.001 & 0.0001 & 0.0001 \\
\cline { 2 - 3 } & Pearson Correlation (r) & & $0.845^{* *}$ & 0.504 \\
\cline { 2 - 3 } \multirow{2}{*}{ MDA } & Pevalue & & 0.0001 & 0.007 \\
\cline { 2 - 3 } & \multicolumn{2}{|r|}{ P-value } & & $0.822^{* *}$ \\
& & & 0.0001 \\
\hline
\end{tabular}

\footnotetext{
*: Significant correlation when $\mathbf{P}<\mathbf{0 . 0 5}$
} 


\section{Correlation analysis:}

All biochemical parameters (VCAM-1, MDA, TNF- $\alpha$ \& Nitrite) showed significant negative correlation with percentage relaxation of NE precontracted aortic rings in response to the three cumulative doses of acetylcholine (Table 3). Significant positive correlations were found between all biochemical parameters. (Table 4)

\section{DISCUSSION}

Endothelial dysfunction is an abnormal reversible functional change of endothelial cells, producing a shift of the endothelial actions toward decreased vasodilatation, pro-inflammatory and prothrombotic properties. It is an early event in the development of cardiovascular diseases. ${ }^{(4,28)} \mathrm{ED}$ is one of the most important extra-articular complications of RA. The use of rat models of arthritis has been considered a unique opportunity to unravel the disease's pathophysiology. Heatkilled Mycobacterium, initially described by Pearson ${ }^{(29)}$, used in the present study is considered to be the most effective model for RA. It is the most widely used method to induce autoimmune disease in rodents, mirroring much of o RA's pathology. ${ }^{(30-32)}$ This model advantage is being reliable, with rapid onset and progression and easily measurable articular manifestations. Clinical signs of arthritis in this model appear 10 to 12 days after injection. In the present study, RA was confirmed clinically on day 11 , and signs of progress in severity were present until the end of the study. This agrees with previous literature which confirmed that RA developed after ten days of immunization and progress in severity for four weeks. ${ }^{(22,33)}$ Regarding the ED assessment in this model, it is usually made when the inflammatory symptoms are maximal (between days 24 and 35 after the injection of Mycobacterium suspension, approximately 14 to 21 days following the onset of arthritis). ${ }^{(34)}$

Several methods have been employed to assess endothelial function. In this study, it was assessed by studying the vascular reactivity of isolated aortic rings to investigate their response to constrictive and relaxant drugs in isometric conditions. Vascular reactivity results revealed a marked significant reduction in Ach-induced relaxation in maximally contracted rings of the non-treated adjuvant-induced arthritis rats versus those of the normal control rats. This is as reported by previous studies (35-37) done 30 days after immunization nearly fourteen to twenty-one days after the onset of arthritis where the endothelial dysfunction was in maximal.

Studying the mechanisms of ED in RA is essential to propose a satisfactory therapeutic strategy for vascular risk prevention. In various cardiovascular diseases, VCAM-1is accepted as a marker of ED. (38) This is following the results of the current study that showed a significant increase in VCAM1 after RA induction in group II in comparison to group I. This is in agreement with the results of Totoson et al (34) that reported that adhesion molecules including VCAM-1 increased at day 11 with maximal levels at day 33 of immunization. The cytokines and turbulent shear stress, accompanying the inflammatory state in RA, induce $\mathrm{NF} \kappa \mathrm{B}$ dependent activation of endothelial cell VCAM-1 expression. (39) VCAM-1 was reported to stimulate intracellular calcium release through its action on calcium channels and this may affect vascular reactivity. ${ }^{(40)}$ This is in line 
with the negative correlation that was found between VCAM-1 and vascular reactivity (acetylcholine-induced relaxation) in the current study.

In addition to VCAM-1, the pro-inflammatory status associated with arthritis might initiate vascular dysfunction. It was reported that in RA, activated $\mathrm{T}$ - cells and macrophages produce proinflammatory mediators such as IL- $1 \beta$ and TNF- $\alpha$, which play an important role in the pathogenesis of RA associated endothelial dysfunction. (41) TNF- $\alpha$ has been shown to inhibit the expression of endothelial nitric oxide synthase (eNOS) through destabilization of eNOS mRNA. ${ }^{(42)}$ Also, TNF- $\alpha$ increases VCAM-1expression on endothelial cells through the activation of the $\mathrm{NF} \kappa \mathrm{B}$ pathway, thereby allowing for leukocyte infiltration in inflamed tissue. ${ }^{(43)}$ In addition, studies in animal models and humans showed a protective effect of anti-TNF- $\alpha$ therapies on blood vessels in inflammatory and cardiovascular diseases. (44- 46) Furthermore, Zhang et al ${ }^{(47)}$ reported that blocking of TNF- $\alpha$ receptor controlled aortic atherosclerosis by reducing VCAM-1 expression in vivo. This is in agreement with the present findings that showed the significant elevation of TNF- $\alpha$ in the untreated rheumatoid group when compared to control group, the significant negative correlation between TNF- $\alpha$ and vascular reactivity and the significant positive correlation between TNF- $\alpha$ with VCAM-1 level. In accordance with the present results, some authors found a positive relationship between circulating inflammatory markers and ED ${ }^{(48,49)}$ whereas others found no link in both early ${ }^{(50)}$ and long-term RA ${ }^{(51)}$.

Malondialdehyde (MDA) is a highly reactive naturally occurring compound. It is considered as a marker for oxidative stress. ${ }^{(52)}$ The results of the current work showed an elevated level of MDA in the untreated rheumatoid group in comparison to the control group. This might be explained by the accumulation of ROS. Oxidative stress was reported previously to play a vital role in the pathophysiology of RA and its associated ED. High concentrations of ROS can activate $\mathrm{NF \kappa B}$ with subsequent increase in aortic endothelial VCAM-1 expression. (53) TNF- $\alpha$ induced VCAM-1 expression is blocked by overexpression of superoxide dismutase. ${ }^{(54)}$ All these findings are following our current results showing that MDA is significantly positively correlated with VCAM-1, while significantly negatively correlated with vascular reactivity.

Change in endothelial nitric oxide (NO) bioavailability is suggested to contribute in endothelial dysfunction in RA patients. NO production in blood vessels could be due to both endothelial NO synthase (eNOS) and inducible NOS (iNOS). Uncoupling of eNOS was found in aorta taken from RA rat. ${ }^{(9,30)}$ Increased activity of inducible nitric oxide synthases (iNOS) is considered to be a key pathophysiological mechanism in RA associated ED. ${ }^{(55)}$ In this study we aimed to evaluate the activity of iNOS. However, because NOS is highly modulated at its post-transcriptional level, NOS expression is not a proper indicator of its activity. ${ }^{(56)}$ Alternatively, plasma levels of nitrite have been postulated as potential biomarkers for NOS activity in the vascular system. (57) Our results showed significant increase in serum nitrite level in the untreated RA group in comparison to the control group which means increased activity of iNOS. Inducible NOS consumes tetrahydrobiopterin co- 
factor (BH4), leading to eNOS uncoupling. Uncoupled eNOS manufactures superoxide anion $\left(\mathrm{O}_{2^{-}}\right)$not NO. Furthermore, when $\mathbf{O}_{2^{-}}$combines with NO, it produces peroxynitrite, a free radical that has no natural antioxidant defense. This process leads to a decrease in bioavailability of endothelial NO in parallel with increased oxidative stress. ${ }^{(8,9)}$ This also in accordance with our results showing negative correlation between nitrite level with Ach induced relaxant effect while showing positive correlation between nitrite level and MDA. In agreement with our results, plasma nitrite levels were found to be increased at day 22 (58) and day 24 post injection in RA rats ${ }^{(59)}$ in addition to a reduced relaxant response of aortic rings to Ach.

Diet plays an essential role in body health and disease status. The important aspect of this study was to evaluate the effect of omega-3 supplementation on the early stage of disease when there is active reversible endothelial dysfunction before the clinical appearance of cardiovascular complications. Omega3 polyunsaturated fatty acids have therapeutic potential in chronic inflammatory diseases. Among the omega-3 PUFAs, docosahexaenoic acid (DHA) and eicosapentaenoic acid (EPA) are more potent than alpha-linolenic acid (ALA). ${ }^{(60)}$ Treatment with omega-3 PUFAs in this study attained a significant improvement of vascular reactivity demonstrated by a significantly enhanced Ach-induced relaxant response in omega-3 treated RA group versus those of the untreated RA rats.

Treatment with omega-3 significantly decreased VCAM-1 in the treated group in comparison to the untreated group. The decrease in the VCAM-1 level was explained by Wang et al ${ }^{(61)}$ showing that polyunsaturated fatty acids decrease VCAM-1 expression by reducing the $\mathrm{NF \kappa B}$ signaling pathway, preservation of $\mathrm{\kappa B}$ inhibitor and prevention of nuclear translocation of NFkB.

Another protective effect of omega-3 on endothelial function is its antioxidant function that was evident in the results of the current work showing a significant decrease in MDA in the treated group when compared to the untreated RA group. This finding is in agreement with other studies showing the antioxidant effect of omega-3 on endothelial function in other models such as chronic kidney disease ${ }^{(62)}$ and ovariectomized rats. (63) Omega-3 PUFA can blunt the activity and expression of NADPH ${ }^{(52)}$, positively modulate the antioxidant potential ${ }^{(64)}$ and therefore reducing oxidative stress. Other studies demonstrated that omega-3 fatty acids (EPA and DHA) were able to displace the omega- 6 fatty acid, arachidonic acid, as molecular substrates during the cyclooxygenase and oxygenase pathway leading to improvement in redox state and reduced omega- 6 fatty acid peroxidation so decreasing ROS production. ${ }^{(65,66)}$ In addition to the previous favorable impacts of omega-3 on VCAM-1 and oxidative stress, omega3 PUFAs are documented to down-regulate proinflammatory processes. ${ }^{(67,68)}$ This is also was present in the current results that showed a significant decrease in TNF- $\alpha$ in omega-3 treated group in comparison to the untreated group. These results agree with other studies in which omega-3 treatment produced a decrease in IL-6 and TNF $\alpha .(69,70)$ This can be explained by the fact that omega -3 fatty acids act as precursors for some lipid mediators called specialized pro-resolving mediators (SPMs). These SPMs are produced by macrophages during the resolution of 
inflammation to stimulate the cessation of polymorphonuclear infiltration. ${ }^{(71)}$

Our results demonstrated also the involvement of NOS enzymes as one of the protective effects of omega-3 fatty acids. The results of the current study showed significant decrease in serum nitrite level in the treated RA group in comparison to the untreated RA group and this suggests beneficial effects of omega-3 through suppression of iNOS activity. The inducible form of NOS is an enzyme that is responsible for forming $\mathrm{NO}$ under pathological conditions. ${ }^{(72)}$ In agreement with our results, other studies found that omega- 3 fatty acids reduced iNOS in hepatic ${ }^{(73)}$ and brain ${ }^{(74)}$ cells. Also, Mayyas et al (75) demonstrated decreased plasma nitrite level in diabetic rats after omega-3 treatment. The effect of omega-3 on nitric oxide synthase is through to be due to its effect on 1-arginine-NO pathway. ${ }^{(76)}$

In conclusion, the findings of this study revealed that induction of rheumatoid arthritis in rats led to reduced vascular reactivity, increased vascular cell adhesion molecule-1, oxidative stress, inflammatory markers and nitrite level. However, omega-3 treatment was effective in the reduction of all measured parameters and improvement of vascular reactivity. Therefore, in addition to the important role of omega-3 in clinical improvement of symptoms of arthritis (77), administration of omega-3 in the present study had a significant therapeutic impact on endothelial dysfunction by decreasing adhesion molecules, an inflammatory marker, oxidative stress and suppression of iNOS activity. So, it is highly recommended to use omega-3 regularly as early as possible in RA cases to protect against this disease's harmful endothelial changes.

\section{Recommendations}

As this study aimed to identify the effects of omega-3 PUFA medical intervention in the early acute stage of the disease, it is recommended to study the effects of omega-3 on the long-term cardiovascular changes in studies of longer duration after occurrence of actual changes in blood pressure and atherosclerosis. Also studying the ultra-structural molecular effects of the medical intervention by electron microscopy is recommended in further studies.

\section{Conflicts of Interest}

The authors declare that there are no conflicts of interest.

\section{$\underline{\text { References }}$}

1. Alamanos Y, Voulgari PV, Drosos AA. Incidence and prevalence of rheumatoid arthritis, based on the 1987 American College of Rheumatology Criteria: a systematic review. Semin Arthritis Rheum $36: 182-8,2006$

2. Aviña-Zubieta JA, Choi HK, Sadatsafavi M, Etminan M, Esdaile JM, Lacaille D. Risk of cardiovascular mortality in patients with rheumatoid arthritis: a meta-analysis of observational studies. Arthritis Rheum 59:1690-7, 2008.

3. Steyers CM, Miller FJ. Endothelial dysfunction in chronic inflammatory diseases. Int J Mol Sci 15: 11324-49, 2014.

4. Versari D, Daghini E, Virdis A, Ghiadoni L, Taddei S. Endothelial dysfunction as a target for prevention of cardiovascular disease. Diabetes Care 32: S314-21, 2009.

5. Kundu S, Ghosh P, Datta S, Ghosh A, Chattopadhyay S, Chatterjee M. Oxidative stress as a potential biomarker for 
determining disease activity in patients with rheumatoid arthritis. Free Radic Res 46: 1482-9, 2012.

6. Kleinbongard P, Heusch G, Schulz R. TNF alpha in atherosclerosis, myocardial ischemia/reperfusion and heart failure. Pharmacol Ther 127: 295-314, 2010.

7. Wang L, Ding Y, Guo X, Zhao Q. Role and mechanism of vascular cell adhesion molecule-1 in the development of rheumatoid arthritis. Exp Ther Med 10: 1229-33, 2015.

8. Maki-Petaja KM, Cheriyan J, Booth AD. Inducible nitric oxide synthase is increased in patients with rheumatoid arthritis and contributes to endothelial dysfunction. Int $\mathbf{J}$ Cardiol 129:399-405, 2008.

9. Haruna Y, Morita Y, Komai N. Endothelial dysfunction in rat adjuvant-induced arthritis: vascular superoxide production by NADPH oxidase and uncoupled endothelial nitric oxide synthase. Arthritis Rheum 54:184755, 2006.

10. Kramer HR, Giles JT. Cardiovascular disease risk in rheumatoid arthritis: progress, debate, and opportunity. Arthritis care res 63(4): 484-99, 2011.

11. Philip C. Omega-3 polyunsaturated fatty acids and inflammatory processes: nutrition or pharmacology? Br J Clin Pharmacol 75(3): 645-62, 2013.

12. Giacobbe J, Benoiton B, Zunszain P, Pariante $\mathrm{CM}$, Borsini A. The anti-Inflammatory role of Omega-3 polyunsaturated fatty acids metabolites in pre-clinical models of psychiatric, neurodegenerative, and neurological disorders. Front Psych 11: 122, 2020.

13. Casós K, Zaragozá MC, Zarkovic N, Zarkovic $\mathrm{K}$, Andrisic L, Portero-Otín M, et al. A fishoil-rich diet reduces vascular oxidative stress in $\operatorname{apoE}(-/-)$ mice. Free Radic Res 44: 821-9, 2010.

14. Ober MD, Hart CM. Attenuation of oxidantmediated endothelial cell injury with docosahexaenoic acid: the role of intracellular iron. Prostaglandins Leukot Essent Fatty Acids 59: 127-35, 1998.

15. Zehr KR, Walker MK. Omega-3 polyunsaturated fatty acids improve endothelial function in humans at risk for atherosclerosis: A review. Prostaglandins Other Lipid Mediat 134: 131-40, 2018.

16. Zebrowska A, Mizia-Stec K, Mizia M, Gasior Z. Omega-3 fatty acids supplementation improves endothelial function and maximal oxygen uptake in endurance-trained athletes. Euro J Sport Sci 15(4): 1-10, 2014.

17. Totoson $\mathrm{P}$, Maguin-Gaté $\mathrm{K}$, Nappey $\mathrm{M}$, Wendling D, Demougeot C. Endothelial dysfunction in rheumatoid arthritis: Mechanistic insights and correlation with circulating markers of systemic inflammation. PLoS One 13; 11(1):e0146744, 2016.

18. Soliman N, Kalleny NK, Abd El Samad AA. Effect of Omega-3 versus Omega-6 fatty acids on induced ulcerative colitis in male albino rat. Light and Electron Microscopic Study. Egypt J Histol 33(4): 620 -34, 2010.

19. Verhoeven F, Totoson P, Maguin-Gate $\mathrm{K}$, Prigent-Tessier A , Marie $\mathrm{C}$, Wendling $\mathrm{D}$, et al. Glucocorticoids improve 
endothelial function in rheumatoid arthritis: a study in rats with adjuvant-induced arthritis. Clin Exp Immunol 188: 208-18, 2017.

20. Friques AG, Arpin CM, Kalil IC. Chronic administration of the probiotic kefir improves the endothelial function in spontaneously hypertensive rats. J Trans Med 13: 390, 2015.

21. Leal MA, Balarini CM, Dias AT, Porto ML. Mechanisms of enhanced vasoconstriction in the mouse model of atherosclerosis: the beneficial effects of sildenafil. Current Pharmaceut Biotech 16 (6): 517-30, 2015.

22. Mossiat C, Laroche D, Prati C, Pozzo T, Demougeot C, Marie C. Association between arthritis score at the onset of the disease and long-term locomotor outcome in adjuvant-induced arthritis in rats. Arthritis Res Ther 17(1): 184, 2015.

23. Chen X, Xum K, Chen L, Wang Y. TNF-alpha, a potent lipid metabolism regulator. Cell Biochem Funct 27(7):407-16, 2009.

24. Aboul-Fotouh SR, Zhang K, Wang D, Jiang Z, Ning X, Buzzacott P, et al. Endothelial dysfunction correlates with decompression bubbles in rats. Sci Rep 6: 33390, 2016.

25. Draper HH, Hadley M. Malondialdehyde determination as index of lipid peroxidation. Methods Enzymol 186: 421-31, 1990.

26. Montgomery HAC, Dymock J. The determination of nitrite in water. Analyst 86: 414-6, 1961.

27. Chan YH. Biostatistics 102: quantitative data-parametric \& nonparametric tests. Singapore Med J 44(8): 391-6, 2003.
28. Mudau M, Genis A, Lochner A, Strijdom H. Endothelial dysfunction: the early predictor of atherosclerosis. Cardiovasc J Afr 23: 222-31, 2012.

29. Pearson CM. Development of arthritis, periarthritis and periotitis in rats given adjuvant. Proc Soc Exp Biol Med 91: 95$101,1956$.

30. Haruna Y, Morita Y, Yada T, Satoh M, Fox DA, Kashihara N. Fluvastatin reverses endothelial dysfunction and increased vascular oxidative stress in rat adjuvantinduced arthritis. Arthritis Rheum 56:182735, 2007.

31. Waksman BH. Immune regulation in adjuvant disease and other arthritis models: relevance to pathogenesis of chronic arthritis. Scand J Immunol 56 (1): 12-34, 2002.

32. Hegen M, Keith JC, Collins M, NickersonNutter CL. Utility of animal models for identification of potential therapeutics for rheumatoid arthritis. Ann Rheum Dis 67:1505-15, 2008.

33. Williams RO. Rodent models of arthritis: relevance for human disease. Clin Exp Immunol 114 (3): 330-2, 1998.

34. Totoson P, Maguin-Gaté K, Nappey M. Microvascular abnormalities in adjuvantinduced arthritis: relationship to macrovascular endothelial function and markers of endothelial activation. Arthritis Rheumatol 67: 1203 -13, 2015.

35. Prati C, Berthelot A, Wendling D, Demougeot C. Endothelial dysfunction in rat adjuvantinduced arthritis: up-regulation of the vascular arginase pathway. Arthritis Rheum 63 (8): 2309-17, 2011. 
36. Prati C, Berthelot A, Kantelip B, Wendling D, Demougeot C. Treatment with the arginase inhibitor Nw-hydroxy-nor-L-arginine restores endothelial function in rat adjuvantinduced arthritis. Arthritis Res Ther 14: 130, 2012.

37. Bordy R, Verhoeven F, Tournier-Nappey $\mathrm{M}$, Wendling D, Demougeot C, Totoson P. Methotrexate did not improve endothelial function in rheumatoid arthritis: $\quad$ a $\quad$ study in rats with adjuvant-induced arthritis. Clin Exp Rheumatol 37(1): 81-8, 2019.

38. Constans J, Conri C. Circulating markers of endothelial function in cardiovascular disease. Clin Chim Acta 368: 33-47, 2006.

39. Kim SR, Bae YH, Bae SK, Choi KS, Yoon $\mathrm{KH}$, Koo TH, et al. Visfatin enhances ICAM-1 and VCAM-1 expression through ROS-dependent NF-kappaB activation in endothelial cells. Biochim Biophys Acta 1783: 886-95, 2008.

40. Cook-Mills JM, Johnson JD, Deem TL, Ochi A, Wang L, Zheng Y. Calcium mobilization and Rac1 activation are required for VCAM-1 (vascular cell adhesion molecule1) stimulation of NADPH oxidase activity. Biochem J 378: 539-47, 2004.

41. Turesson C, Jacobsson LTH, Matteson EL. Cardiovasular co-morbidity in rheumatic disaeases. Vascular health and risk management 4(3): 605-16, 2008.

42. Sun HX, Zeng DY, Li RT, Pang RP, Yang, H., $\mathrm{Hu} \mathrm{YL}$, et al. Essential role of microRNA155 in regulating endothelium-dependent vasorelaxation by targeting endothelial nitric oxide synthase. Hypertension 60: 1407-14, 2012.

43. Yan S, Zhang $\mathrm{X}$, Zheng $\mathrm{H}$, Hu D, Zhang Y, Guan Q, et al. Clematichinenoside inhibits VCAM-1 and ICAM-1 expression in TNF- $\alpha$-treated endothelial cells via NADPH oxidase-dependent I $\kappa$ B kinase/NFKb pathway. Free Radic Biol Med 78:190201, 2015.

44. Pires PW, Girgla SS, Moreno G, McClain J, Dorrance AM. Tumor necrosis factor- $\alpha$ inhibition attenuates middle cerebral artery remodeling but increases cerebral ischemic damage in hypertensive rats. Am J Physiol Heart Circ Physiol 307(5): H58-69, 2014.

45. Vlachopoulos C, Gravos A, Georgiopoulos G, Terentes-Printzois D, Ioakeimidis N, Vassilopoulos D, et al. The effect of TNF- $\alpha$ antagonists on aortic stiffness and wave reflections: a meta-analysis. Clin Rheumatol 37(2): 515-26, 2018.

46. Cai R, Hao Y, Liu YY, Lei Huang L, Yao Y, Zhou MS. Tumor necrosis factor alpha deficiency improves endothelial function and cardiovascular injury in deoxycorticosterone acetate/salthypertensive mice. Biomed Res Int 2020: 3921074, 2020.

47. Zhang L, Peppel K, Sivashanmugam P, Orman ES, Brian L, Exum ST, et al. Expression of tumor necrosis factor receptor-1 in arterial wall cells promotes atherosclerosis. Arterioscler Thromb Vasc Biol 27(5): 108794, 2007.

48. Södergren A, Karp K, Boman K, Eriksson C, Lundström E, Smedby T, et al. Atherosclerosis in early rheumatoid arthritis: 
very early endothelial activation and rapid progression of intima media thickness. Arthritis Res Ther 12: R158, 2010.

49. Dessein PH, Joffe BI, Singh S. Biomarkers of endothelial dysfunction, cardiovascular risk factors and atherosclerosis in rheumatoid arthritis. Arthritis Res Ther 7: R634-43, 2005.

50. Foster W, Lip GY, Raza K, Carruthers D, Blann AD. An observational study of endothelial function in early arthritis. Eur J Clin Invest 42: 510-6, 2012.

51. Sandoo A, Kitas GD, Carroll D, Veldhuijzen van Zanten JJ. The role of inflammation and cardiovascular disease risk on microvascular and macrovascular endothelial function in patients with rheumatoid arthritis: a crosssectional and longitudinal study. Arthritis Res Ther 14: R117, 2012.

52. Del Rio D, Stewart AJ, Pellegrini N. A review of recent studies on malondialdehyde as toxic molecule and biological marker of oxidative stress. Nutr Metab Cardiovasc Dis 15 (4): 316-28, 2005.

53. Lee S, Chung J, Ha IS, Yi K, Lee JE, Kang $\mathrm{HG}$, et al. Hydrogen peroxide increases human leukocyte adhesion to porcine aortic endothelial cells via NFkappa B-dependent up-regulation of VCAM-1. Int Immunol 19: 1349-59, 2007.

54. Chen XL, Zhang Q, Zhao R, Ding X, Tummala PE, Medford RM. Rac1 and superoxide are required for the expression of cell adhesion molecules induced by tumor necrosis factoralpha in endothelial cells. J Pharmacol Exp Ther 305: 573-80, 2003.
55. Tozzato GPZ, Taipeiro EF, Spadella MA, Marabini Filho P, de Assis MR, Carlos CP, Girol AP, et al. Collagen-induced arthritis increases inducible nitric oxide synthase not only in aorta but also in the cardiac and renal microcirculation of mice. Clinical and Experimental Immunology, 183: 341-9, 2015.

56. Piech A, Dessy C, Havaux X, Feron O, Balligand JL. Differential regulation of nitric oxide synthases and their allosteric regulators in heart and vessels of hypertensive rats. Cardiovasc Res 57:45667, 2003.

57. Burger D, Touyz RM: Cellular biomarkers of endothelial health: microparticles, endothelial progenitor cells, and circulating endothelial cells. J Am Soc Hypertens 6:8599, 2012.

58. Hua J, Suguro S, Hirano S, Sakamoto K, Nagaoka I. Preventive actions of a high dose of glucosamine on adjuvant arthritis in rats. Inflamm Res 54:127-32, 2005.

59. Nozaki K, Goto H, Nakagawa T, Hikiami H, Koizumi K, Shibahara N, Shimada Y. Effects of keishibukuryogan on vascular function in adjuvant-induced arthritis rats. Biol Pharm Bull 30:1042-7, 2007.

60. Shahidi F, Ambigaipalan P. Omega-3 polyunsaturated fatty acids and their health benefits. Annu Rev Food Sci Technol 9: 345-81, 2018.

61. Wang TM, Chen CJ, Lee TS, Chao HY, Wu WH, Hsieh SC, et al. Docosahexaenoic acid attenuates VCAM-1 expression and NF- $\mathrm{KB}$ activation in TNF- $\alpha$-treated human aortic 
endothelial cells. J Nutr Biochem 221: 87194, 2011.

62. Zanetti M, Gortan Cappellari G, Barbetta D, Semolic A, Barazzoni R. Omega 3 polyunsaturated fatty acids improve endothelial dysfunction in chronic renal failure: Role of eNOS activation and of oxidative stress. Nutrients 18; 9(8):895, 2017.

63. Cappellari G, Losurdo P, Mazzucco S, Panizon E, Jevnicar M, Macaluso L, et al. Treatment with omega-3 polyunsaturated fatty acids reverses endothelial dysfunction and oxidative stress in experimental menopause. J Nutr Biochem 24(1): 371-9, 2013.

64. Qi X, Qin Z, Tang J, Han P, Xing Q, Wang K, et al. Omega-3 polyunsaturated fatty acids ameliorates testicular ischemia-reperfusion injury through the induction of $\mathrm{Nrf} 2$ and inhibition of NF-kB in rats. Exp Mol Pathol 24: 30282-4, 2017.

65. Davis TA, Gao L, Yin H, Morrow JD, Porter NA. In vivo and in vitro lipid peroxidation of arachidonate esters: the effect of fish oil omga-3 lipids on product distribution. J Am Chem Soc 128: 14897-904, 2006.

66. Miller PE, Van Elswyk M, Alexander DD. Long-chain omega-3 fatty acids eicosapentaenoic acid and docosahexaenoic acid and blood pressure: a meta-analysis of randomized controlled trials. Am J Hypertens 27: 885- 96, 2014.

67. Ferguson JF, Roberts-Lee K, Smith HM, Midgette Y, Shah R. Omega-3 polyunsaturated fatty acids attenuate inflammatory activation and alter differentiation in human adipocytes. J Nutr Biochem 64: 45-9, 2019.

68. Mocellin MC, Fernandes R, Chagas TR, Trindade EB. A meta-analysis of n-3 polyunsaturated fatty acids effects on circulating acute-phase protein and cytokines in gastric cancer. Clin Nutr 37: 840-50, 2018.

69. Korner A, Schlegel M, Theurer J, Frohnmeyer H, Adolph M, Heijink M, et al. Resolution of inflammation and sepsis survival are improved by dietary $\Omega-3$ fatty acids. Cell Death Differ 25: 421-31, 2018.

70. Mickleborough TD, Sinex JA, Platt D, Chapman RF, Hirt M. The effects PCSO$524 \AA$, a patented marine oil lipid and omega-3 PUFA blend derived from the New Zealand green lipped mussel (Pernacanaliculus), on indirect markers of muscledamage and inflammation after muscle damaging exercise in untrained men: a randomized, placebo controlled trial. J Int Soc Sports Nutr 12: 10, 2015.

71. Serhan CN. Pro-resolving lipid mediators are leads for resolution physiology. Nature 510: 92-101, 2014.

72. Broom L, Marinova-Mutafchieva L, Sadeghian M, Davis JB, Medhurst AD, Dexter DT. Neuroprotection by the selective iNOS inhibitor GW274150 in a model of Parkinson disease. Free Radical Biol Med 50(5):633-40, 2011.

73. Araki Y, Matsumiya M, Matsuura T, Oishi M, Kaibori M, Okumura T, et al. Peroxidation of n-3 polyunsaturated fatty acids inhibits the induction of iNOS gene expression in proinflammatory cytokine-stimulated 
hepatocytes. J Nutr Metab 2011:374542, 2011.

74. Shen J, Hafeez A, Stevenson J, Yang J, Yin $\mathrm{Y}, \mathrm{Li} \mathrm{F}$, et al. Omega-3 fatty acid supplement prevents development of intracranial atherosclerosis. Neurosci 15:226-35, 2016.

75. Mayyas F, Jaradat R, Alzoubi K. Cardiac effects of fish oil in a rat model of streptozotocin-induced diabetes. Nutr Metab Cardiovasc Dis 28:6, 2018.

76. Martins MA, Moss MB, MendesIK, Águila $\mathrm{M}$, de-Lacerda $\mathrm{C}$, Brunini $\mathrm{T}$, et al. Role of dietary fish oil on nitric oxide synthase activity and oxidative status in mice red blood cells. Food Funct 5: 3208-15, 2014.

77. Morin C, Blier PU, Fortin S. Eicosapentaenoic acid and docosapentaenoic acid monoglycerides are more potent than docosahexaenoic acid monoglyceride to resolve inflammation in a rheumatoid arthritis model. Arthritis Res Ther 17:142, 2015. 